\title{
Short term increase in risk of breast cancer after full term pregnancy
}

\author{
Paolo Bruzzi, Eva Negri, Carlo La Vecchia, Adriano Decarli, Domenico Palli, Fabio Parazzini, \\ Marco Rosselli Del Turco
}

\begin{abstract}
To determine whether there is a short term increase in the risk of breast cancer after a full term birth data from two hospital based, case-control studies in Italy were pooled. Analysis was restricted to women aged under 50 with two or more children ( 573 women with cancer and 570 controls). A relative risk for breast cancer of 2.66 was seen in women who had given birth during the three years preceding the interview compared with women whose last birth had occurred 10 or more years before, after adjustment for age, age at first birth, and parity. The relative risk slowly decreased for women who had last given birth three to 10 years before. Multivariate analyses confirmed the protective effect of an early age at first birth and the age dependent effect of parity on the risk of breast cancer-that is, a direct relation below age 40 and an inverse one in older women.
\end{abstract}

These data provide epidemiological evidence that a full term birth is followed by a transient increase in the risk of breast cancer, which for some time contrasts with and overcomes the long term protection of pregnancy at an early age. They therefore confirm predictions from animal studies and theoretical models that pregnancy prevents the early stages of breast carcinogenesis but promotes the late stages of the process.

\section{Introduction}

The role of several reproductive factors in the risk of breast cancer are recognised ${ }^{12}$ : having the first baby when young has a protective effect, and further protection seems to be afforded by subsequent pregnancies, especially those at an early age..$^{3-5}$ Protection seems to be associated only with full term pregnancies. First births occurring after the age of 28-30 years do not seem to have a protective effect, and women aged over 32 at their first birth seem to have a higher risk of breast cancer than nulliparous women. Several studies, however, have reported that during their reproductive years parous women are at a higher risk of breast cancer than nulliparous women, ${ }^{6-9}$ and it has been suggested that as well as conferring long term protection pregnancy results in a short term increase in the risk of breast cancer. ${ }^{10} 11$ No direct epidemiological evidence on the size and duration of this increase has been presented. To investigate this issue we used the original data from two large case-control studies of breast cancer, which were carried out in several regions of Italy between 1980 and 1986 .

\section{Patients and methods}

The designs and methods of the two case-control studies were described in the original papers. ${ }^{1213}$ Briefly, the first study was a hospital based investigation carried out between 1980 and 1983 in 13 breast cancer clinics in 10 different Italian provinces; eight in northern Italy (75\% of the cases), one in central Italy $(20 \%)$, and one in the south (5\%). ${ }^{12}$ A total of 1556 women with newly diagnosed cancer (confirmed histologically or cytologically, or both) were interviewed and compared with 1505 controls who had been admitted for acute orthopaedic, medical, or surgical conditions unrelated to known or suspected risk factors for breast cancer. Though matching was not strictly respected, the distribution of cases and controls according to province of residence was satisfactorily comparable.

The second study was a hospital based case-control study; the cases comprised 1663 women with breast cancer that had been histologically confirmed. The women were aged less than 75 and were admitted from January 1983 to December 1986 to the National Cancer Institute, Milan, and the Ospedale Maggiore (which includes the four largest teaching and general hospitals in Milan). The group for comparison consisted of 1741 women admitted to the same network of hospitals for acute conditions (30\% trauma, $25 \%$ orthopaedic, $18 \%$ surgical, $27 \%$ miscellaneous). The controls were comparable with the patients with cancer in terms of age and area of residence.

The following information was abstracted from the original data files of the two studies: age, age at first full term birth, age at last birth, and number of births. A single file was created, which included these items plus the case-control state and the centre of enrolment.

The aim of the study was to detect any short term increase in risk after a full term pregnancy. Consequently the variable under study was defined as the number of years since last birth, which was arbitrarily classified as $<3$ years, 3-6 years, 7-9 years, and 10 years and over. The last class was used as a reference. The variable is obviously related to age, age at first full term birth, and parity, which are risk factors for breast cancer. All these factors plus the centre of enrolment were included in a multiple logistic regression model to obtain estimates of relative risk of breast cancer together with their $95 \%$ confidence intervals. ${ }^{14}$ The analysis was restricted to women with two or more children, as for primiparous women years since last birth was equal to age minus age at first birth, and to women aged less than 50 because among older women years since last birth was generally greater than 10 . The generalised linear interactive modelling package ${ }^{15}$ was used to obtain estimates of maximum likelihood for the model's variables, and tests for linear trends were used for multiple levels of exposure.

\section{Results}

Table I shows the characteristics of the 573 patients with cancer and 570 controls who met the criteria for inclusion ( $<50$ years old and two or more births).

Years since last birth-Table II shows the results of the multivariate analysis. A significant trend of increasing risk with decreasing number of years since last birth was observed $(p<0.01)$. When compared with women of similar age, age at first full term birth, and parity and whose last birth had occurred 10 or more years before the interview, those whose last birth had occurred 7-9 years, 3-6 years, and $<3$ years before the interview had a relative risk of breast cancer of 1.37 , $1 \cdot 81$, and $2 \cdot 66$, respectively. No difference in risk was observed between women whose last baby had been born $10-15$ years and $\geqslant 16$ years previously. When the women were split into two groups according to age ( $<40$ and 40-49; table III) the effect was more pronounced in the older age group, but the confidence intervals of the relative risk estimates largely overlapped.

Age at first full term birth and parity-A direct relation
Correspondence to: Dr Bruzzi. 
TABLE I-Distribution of 573 women with breast cancer and 570 controls according to selected variables. Values are numbers (percentages)

\begin{tabular}{lrr}
\hline & $\begin{array}{c}\text { Women with breast } \\
\text { cancer }\end{array}$ & Controls \\
\hline $\begin{array}{l}\text { Age (years): } \\
<30\end{array}$ & $5(0 \cdot 9)$ & $32(5 \cdot 6)$ \\
$30-34$ & $31(5 \cdot 4)$ & $61(10 \cdot 7)$ \\
$35-39$ & $95(16 \cdot 6)$ & $136(23 \cdot 9)$ \\
$\quad 40-49$ & $442(77 \cdot 1)$ & $341(59 \cdot 8)$ \\
Age at first full term birth (years): & & \\
$\leqslant 20$ & $65(11 \cdot 3)$ & $150(26 \cdot 3)$ \\
$21-22$ & $91(15 \cdot 9)$ & $109(19 \cdot 1)$ \\
$23-24$ & $121(21 \cdot 1)$ & $110(19 \cdot 3)$ \\
$25-27$ & $165(28 \cdot 8)$ & $127(22 \cdot 3)$ \\
$28-31$ & $107(18 \cdot 7)$ & $54(9 \cdot 5)$ \\
$\geqslant 32$ & $24(4 \cdot 2)$ & $20(3 \cdot 5)$ \\
No of births: & & \\
2 & $388(67 \cdot 7)$ & $385(67 \cdot 5)$ \\
3 & $131(22 \cdot 9)$ & $125(21 \cdot 9)$ \\
$\geqslant 4$ & $54(9 \cdot 4)$ & $60(10 \cdot 5)$ \\
Time since last birth (years): & & \\
$\geqslant 10$ & $341(59 \cdot 5)$ & $333(58 \cdot 4)$ \\
$7-9$ & $127(22 \cdot 2)$ & $118(20 \cdot 7)$ \\
$3-6$ & $76(13 \cdot 3)$ & $86(15 \cdot 1)$ \\
$<3$ & $29(5 \cdot 1)$ & $33(5 \cdot 8)$ \\
& & \\
& &
\end{tabular}

TABLE II - Relative risks of breast cancer among 573 cases and 570 controls aged $<50$ who had had two or more children

\begin{tabular}{|c|c|}
\hline & $\begin{array}{l}\text { Relative risk } \\
\text { (95\% confidence } \\
\text { intervals) }\end{array}$ \\
\hline \multicolumn{2}{|c|}{ Years since last birth: } \\
\hline$\geqslant 10$ & 1 (reference) \\
\hline $7-<10$ & $1.37(0.97$ to 1.94$)$ \\
\hline $3-<7$ & $1.81(1.13$ to 2.90$)$ \\
\hline$<3$ & $2.66(1.31$ to 5.39$)$ \\
\hline$\chi_{1}^{2}$ for trend & $9.88(\mathrm{p}<0.01)$ \\
\hline \multicolumn{2}{|c|}{ Age at first birth: } \\
\hline$\leqslant 20$ & 1 (reference) \\
\hline $21-22$ & $1 \cdot 79(1 \cdot 17$ to $2 \cdot 71)$ \\
\hline $23-24$ & $2.07(1.37$ to 3.11$)$ \\
\hline $25-27$ & $2.05(1.36$ to 3.08$)$ \\
\hline $28-31$ & $2.84(1.75$ to 4.60$)$ \\
\hline$\geqslant 32$ & $1.43(0.68$ to 2.97$)$ \\
\hline$\chi_{1}^{2}$ for trend & $11.64(\mathrm{p}<0.01)$ \\
\hline \multicolumn{2}{|l|}{ No of births: } \\
\hline 2 & 1 (reference) \\
\hline 3 & $0.94(0.69$ to 1.27$)$ \\
\hline$\geqslant 4$ & $0.79(0.50$ to 1.23$)$ \\
\hline$\chi_{1}^{2}$ for trend & $1.02(\mathrm{NS})$ \\
\hline
\end{tabular}

«Derived from logistic model including age, centre, and variables above. existed between age at first full term birth and risk of breast cancer in the age groups $<40$ and $40-49$, but no notable difference in the effect of age at first birth was observed between the two groups. There was an overall trend of decreasing risk with increasing parity, which fell short of significance. The role of increased parity, however, was different in the two age groups: among younger women increasing parity was associated with an increasing risk, though not significantly so. Among women aged 40-49 increasing parity was associated with a decreasing risk, this trend being of borderline significance $\left(\chi^{2}\right.$ test, $\left.p=0 \cdot 06\right)$.

TABLE III-Relative risk ${ }^{\star}$ ( $95 \%$ confidence intervals) in two age groups of women who had had two or more children

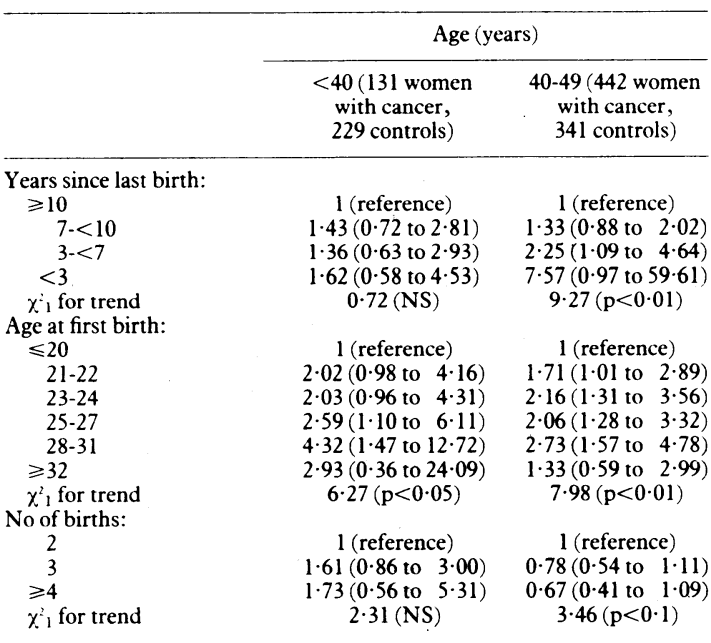

^Derived from logistic models including age, centre, and variables above.

\section{Discussion}

Our data provide direct evidence that a full term pregnancy at any age is followed by a transient increase in the risk of breast cancer over and above the increase associated with aging alone. This increase for some time masks the long term protection afforded by the pregnancy.

Animal studies suggest that the decrease in the lifetime risk of breast cancer in parous women is due to differentiation of mammary glands induced by full term pregnancy, which makes them less susceptible to carcinogenic stimuli. ${ }^{16}$ Conversely, pregnancy after the administration of a carcinogen to virgin rats increased the incidence of tumours. The significant trend of increasing risk with increasing age at first full term birth, which has been reported by most epidemiological studies, can be attributed to the length of the period when the breasts are susceptible to carcinogens, which depends on the presence and concentration of undifferentiated structures. The protective effect of increasing parity after adjustment for age at first birth can be explained by the extended differentiation induced by repeated pregnancies. Two observations, however, are not accounted for by this explanation: the higher risk associated with a late age at first full term birth than with nulliparity, and the decreased risk of nulliparous women during reproductive years. A different effect of pregnancy has therefore been hypothesised, ${ }^{7}{ }^{10}$ which is confirmed by our results. In our study the difference in the effect of increasing parity between women aged under 40 and those aged $40-49$ can be interpreted as supporting this hypothesis; pregnancies between the first and the last are generally more recent among younger women than among older women, and the increased risk associated with these pregnancies will still be present.

Our results fit the predictions from the standard multistage theory of carcinogenesis ${ }^{17} 18$ as well as from a more formal two stage model of breast carcinogenesis proposed by Moolgavkar et al to interpret epidemiological features of breast cancer. ${ }^{19}$ Within the two stage model we can assume that a pregnancy acts as an antiinitiator, by reducing the pool of susceptible stem cells through differentiation, and as a promoter, by expanding the clone of initiated cells. Different hormonal mechanisms are likely to have a role in these two effects. ${ }^{20}$ The model predicts a long term protection inversely proportional to the age at pregnancy and a short term increase in risk that in relative terms is independent of age at pregnancy. These were exactly our findings.

A transient increase lasting five to 10 years in the risk of breast cancer after a full term pregnancy was also predicted by Pike et al, ${ }^{21}$ who derived a statistical model that incorporated most of the epidemiological evidence on breast cancer. To obtain a satisfactory fit they had to include a constant to represent a one time increase in the rate of "breast tissue aging," the "relevant age" of the tissue being assumed to be the critical determinant of the incidence of breast cancer that incorporates the effects of all the risk factors for breast cancer related to hormones.

Regarding the size and duration of the increased risk, our data showed a relative risk of between two and three in the first three years after birth, which slowly decreased thereafter and was more pronounced in those aged 40-49. In the light of the large confidence intervals of the relative risk estimates, however, our findings should be confirmed by further work.

This work was part of the Italian National Research Council's applied project on oncology. We acknowledge contributions from the Italian Association for Cancer Research and the Italian League Against Tumours (contracts number 82.0042596 (coordinator A Toti, University of Terrara), 85.00487.56, and 85.00549.56). We thank Professor A Piffanelli (Institute of Radiology, University of Ferrara) for his help in the Italian multicentric case-control study on breast cancer, and the Interuniversity Consortium of Lombardy for Automatic Data Processing for the use of computer facilities.

1 Kelsey JL. A review of the epidemiology of human breast cancer. Epidemiol Rev 1979;1:74-109.

2 Thomas DB. Epidemiologic and related studies of breast cancer etiology. In: Lilienfeld AM, ed. Reviews in cancer epidemiology. Vol 1. Elsevier: New York, 1980:153-217.

3 Helmrich SP, Shapiro S, Rosemberg L, et al. Risk factors for breast cancer. Am $\mathcal{F}$ Epidemiol 1983;117:35-45.

4 Tulinius H, Day NE, Johannesson G, et al. Reproductive factors and risk for breast cancer in Iceland. Int $\mathcal{F}$ Cancer 1978;21:724-30.

5 Trichopoulos D, Hsieh CC, MacMahon B, et al. Age at any birth and breast cancer risk. Int $\mathcal{f}$ Cancer 1983;31:701-4. 
6 Lubin JH, Burns PE, Blot WJ, et al. Risk factors for breast cancer in women in northern Alberta, Canada, as related to age at diagnosis. $7 N C I$ 1982;68: 211-7.

7 Janerich DT, Hoff MB. Evidence for a cross-over in breast cancer risk factors. Am 7 Epidemiol 1982;116:737-42.

8 Ron E, Lubin F, Wax Y Re: "Evidence for a cross-over in breast cancer risk factors." Am f Epidemiol 1984;119:139-40.

9athak DR, Speizer FE, Willet WC, al Parity and breast cancer risk: possible effect on age at diagnosis. Int $\mathcal{F}$ Cancer 1986;37:21-5.

10 Woods KL, Smith SR, Morrison JM. Parity and breast cancer: evidence of dual effect. BrMed f 1980;281:419-21.

11 Miller $\mathrm{AB}$, Bulbrook RD. UICC multidisciplinary project on breast cancer: the epidemiology, aetiology and prevention of breast cancer. Int $\mathcal{F}$ Cancer 986;37:173-7.

2 Toti A, Agugiaro S, Amadori D, et al. Breast cancer risk factors in Italian women: a multicentric case-control study. Tumori 1986;72:241-9.

13 La Vecchia C, Decarli A, Parazzini F, et al. General epidemiology of breast cancer in northern Italy. Int I E pidemiol 1987; 16:347-55.

14 Breslow NE, Day NE. Statistical methods in cancer research. Lyons:
International Agency for Research on Cancer, 1980. (IARC Scientific Publications No 32 .

15 Baker RJ, Nelder JA. The GLIM system. Oxford: Numerical Algorithms Group, 1978

16 Russo J, Tay LK, Russo IH. Differentiation of the mammary gland and susceptibility to carcinogenesis. Breast Cancer Res Treat 1982;2:5-73.

17 Peto R. Epidemiology, multistage models, and short term mutagenicity tests. In: Hiatt $\mathrm{HH}$, Watson JD, Winsten JA eds. Oring of human In: Hiatt HH, Watson JD, Winsten JA, eds. Origins of human cancer. Cold 18 Day NE, Brown CC. Multistage models and primary prevention of cancer. fNCI 1980;64:977-89.

19 Moolgavkar SH, Day NE, Stevens RG. Two-stage model for carcinogenesis epidemiology of breast cancer in females. 7 NCI 1980;65:559-69.

20 Russo IH, Russo J. From pathogenesis to hormone prevention of mammary carcinogenesis. Cancer Surv 1986;5:649-70.

21 Pike MC, Krailo MD, Henderson BE, et al. "Hormonal" risk factors, "breas tissue age" and the age-incidence of breast cancer. Nature 1983;303:767-70

(Accepted 28 fune 1988)

\title{
Increased mortality of preterm infants transferred between tertiary perinatal centres
}

\author{
Ellen Bowman, Lex W Doyle, Laurence J Murton, R Neil D Roy, William H Kitchen
}

\begin{abstract}
Over 18 months almost one quarter of infants born before 30 weeks' gestation in a tertiary perinatal centre who required intensive care had to be transferred to other tertiary centres because intensive care facilities were fully occupied. When infants with lethal congenital malformations were excluded half of the 34 infants who were transferred died; this was twice the mortality (24\%) in the 111 infants remaining. The difference between the groups was significant (relative odds $=3 \cdot 1$ ) and remained so after adjustment for any discrepancies in gestational age (relative odds $=4 \cdot 0$ ). After adjustment for potential confounding variables by logistic function regression the risk of dying for those transferred remained significantly higher than that for infants who remained (relative odds $=4.6,95 \%$ confidence interval $1 \cdot 8$ to $12 \cdot 1$ ).
\end{abstract}

As the requirement for neonatal intensive care is episodic and unpredictable more flexibility has to be built into the perinatal health care system to enable preterm infants delivered in tertiary perinatal centres to be cared for where they are born.

\section{Introduction}

Mortality in preterm infants increases with decreasTransport Service (NETS) Victoria, Australia Ellen Bowman, FRACP, deputy director

R Neil D Roy, FRACP, director

Division of Paediatrics, Royal Women's Hospital, Melbourne

Laurence J Murton, FRACP, director of neonatal intensive care unit

\section{Departments of Obstetrics} and Gynaecology, University of Melbourne, Parkville, 3052 Melbourne Lex W Doyle, FRACP, senior lecturer

William H Kitchen, FRACP, first assistant

Correspondence to: $\mathrm{Dr}$ Doyle. influences survival is being born outside a tertiary perinatal centre; transferring such infants to tertiary centres improves their survival. ${ }^{1}$ We studied the fate of preterm infants born in one tertiary centre who required intensive care but had to be transferred to other centres because of lack of facilities in the hospital of birth.

\section{Patients and methods}

During 18 months from 1 January 1986 there were Melbourne, the largest of the three tertiary perinatal centres in the state of Victoria. After birth 396 (4\%) infants required intensive care. Criteria for admission to the intensive care unit included the need for assisted ventilation or an indwelling arterial line. Over the 18 months $63(16 \%)$ of these infants born in other centres (two perinatal, one neonatal only) in Melbourne because the intensive care facilities were full.
Data on perinatal variables likely to influence survival were recorded (table I). The obstetrician's estimate of gestation, based on menstrual history or early ultrasound examination, or both, was accepted as accurate. Babies with lethal congenital abnormalities and those transferred immediately after birth because they needed a major operation (unavailable in our hospital) were excluded from the final analysis. As infants born at $\geqslant 30$ weeks' gestation are likely to survive whether they are transferred or not we were particularly interested in the outcome of those born at $<30$ weeks' gestation.

In infants born before 30 weeks' gestation mortality was compared between the group who stayed in the hospital of birth and the group transferred, firstly, by $\chi^{2}$ analysis with no adjustment for confounding factors; secondly, by the Mantel-Haenszel $\chi^{2}$ test with adjustment for gestational $\mathrm{age}^{2}$; and, finally, by logistic function regression with adjustment for other variables, listed in table I. Table $I$ also shows the proportion of babies intubated by the time of the first analysis of blood gas tensions and the ventilator settings for those infants; these variables give an assessment of the severity of respiratory disease in the first hours after birth. To see whether mortality might

TABLE I-Perinatal variables in preterm infants (24-29 weeks' gestation) remaining in hospital of birth or transferrd to another tertiary perinatal centre (infants with lethal congenital abnormalities were excluded) 10455 live births at the Royal Women's Hospital, the hospital had to be transferred to one of three

\begin{tabular}{|c|c|c|}
\hline Perinatal variable & $\begin{array}{l}\text { Infants } \\
\text { remaining } \\
(\mathrm{n}=111)\end{array}$ & $\begin{array}{c}\text { Infants } \\
\text { transferred } \\
(\mathbf{n}=34)\end{array}$ \\
\hline $\begin{array}{l}\text { Mean (SD) gestational age (completed } \\
\text { weeks) } \\
\text { Mean (SD) birth weight (g) } \\
\text { Mean (SD) inspired oxygen (\%) } \\
\text { Median (interquartile range) Apgar score: } \\
\text { At } 1 \text { minute } \\
\text { At } 5 \text { minutes } \\
\text { Median (interquartile range) time to first } \\
\text { arterial blood gas analysis (minutes) } \\
\text { No (\%) male } \\
\text { No }(\%) \text { transferred in utero } \\
\text { No }(\%) \text { resulting from multiple pregnancies } \\
\text { No }(\%) \text { intubated }{ }^{\star}\end{array}$ & $\begin{array}{c}27 \cdot 3(1 \cdot 4) \\
1023(256) \\
66 \cdot 4(22 \cdot 8) \\
5(3 \text { to } 6) \\
8(7 \text { to } 9)\end{array}$ & $\begin{array}{c}27 \cdot 0 \quad(1 \cdot 5 \\
1002(265) \\
62 \cdot 1 \quad(20 \cdot 0 \\
\\
5 \quad(4 \text { to } 7) \\
8(7 \text { to } 9)\end{array}$ \\
\hline \multicolumn{3}{|c|}{ Intubated infants ${ }^{\star}$} \\
\hline $\begin{array}{l}\text { Mean }(\mathrm{SD}) \text { inspired oxygen }(\%) \\
\text { Mean }(\mathrm{SD}) \text { peak pressure }\left(\mathrm{cm} \mathrm{H}_{2} \mathrm{O}\right) \\
\text { Mean }(\mathrm{SD}) \text { end expiratory pressure } \\
\quad\left(\mathrm{cm} \mathrm{H}_{2} \mathrm{O}\right) \\
\text { Mean }(\mathrm{SD}) \text { ventilator rate (breaths/minute) }\end{array}$ & $\begin{array}{r}69 \cdot 7(22 \cdot 2) \\
20 \cdot 7(5 \cdot 1) \\
4 \cdot 6(0 \cdot 5) \\
41 \cdot 5(10 \cdot 0)\end{array}$ & $\begin{array}{l}63 \cdot 3(19 \cdot 7) \\
20 \cdot 3(4 \cdot 0)\end{array}$ \\
\hline
\end{tabular}

$\star$ At time of first blood gas analysis. $\dagger p<0.001, \neq p=0.04$. 